\title{
The Relation between Parenting Stress and Marital Satisfaction of Mother with Efficacy Students with Visual Impairment, a Relation Design
}

Nooshin Asadi ${ }^{1}$ *

\section{ABSTRACT}

Introduction: Evidence suggests that parents of children with mental or physical problems are more likely to have encountered numerous problems. Objective: The presented study was conducted with aim to determine the relation between marital satisfaction and parenting stress of mothers with efficacy in students with visual impairment. Method: this plan carried out in the area of descriptive studies in the form of causal-comparative study. The target formed the population included all male students with visual impairment living in Tehran and Karaj. For this purpose sixty ( $\mathrm{N}=60$ ) Students (age range 22-12, with average age: 18.2) were selected by available sampling method .Data collection was used on survey methods to assess index of parenting stress, marital satisfaction and self-efficacy questionnaire work by Schafer (response rate $=93 \%$ ), Enrich (response rate $=90 \%$ ) and general self-efficacy (response rate $=89 \%$ ). Data collected were used with the help of Pearson correlation test, F-test and regression analysis. As well as qualitative data were analyzed obtained from the assessment coding demographic and qualitative data analysis tool Atlas.ti-5.2. Results: Data analysis showed that amount of stress between parenting stress and marital satisfaction with self-efficacy of children is significant. In this regard, parenting stress of mothers was determined by three variance levels of academic selfefficacy $(r=-0.35)$, Social $(r=-0.27)$ and emotional $(r=-0.28)$. The results showed that women share of parenting stress in mothers in define of self-efficacy students was higher than the share of marital satisfaction. Conclusion: As the research literature shows, the results reflect the tension between the components of marital satisfaction; styles of parenting and students' selfefficacy, the findings also offer preventive implications that could be important in the area of applications.

Keywords: Self-Efficacy, Parenting Stress Of Mothers, Maternal Marital Satisfaction.

\footnotetext{
${ }^{1}$ M.A in Exceptional Children, Central Tehran of Azad University, Tehran, Iran

*Responding Author

(C) 2016 I N Asadi; licensee IJIP. This is an Open Access Research distributed under the terms of the Creative Commons Attribution License (http://creativecommons.org/licenses/by/2.0), which permits unrestricted use, distribution, and reproduction in any Medium, provided the original work is properly cited.
} 


\section{The Relation between Parenting Stress and Marital Satisfaction of Mother with Efficacy Students with Visual Impairment, a Relation Design}

One of the most natural Groups that can satisfy the Needs of a Man is a Family. Duty of Family is to protect and train Children, Establishing Healthy connections of family members with each other And Help Toward independence of Children, Even If the Child is mentally Retarded, blindness or feafness. Blindness is a Special Condition and situation that appears in the effect of different terms Before or after Birth (Michaeli, 1387). Certainly birth and presence of children with vision problems can be considered an adverse event and challenging in every household, which may follow with stress, frustration, sadness and despair. several evidences show that parents of children with mental or physical problems are more likely to have emotional problems, limiting economic and social nature often with devastating and pervasive encounters, (Khamis, 2007). Although all family members and their functions in such a situation are damaged (Hearing et al., 2006) due to the traditional role of mothers 'Watchmen', they assume more responsibilities for their children which as a result, they encounter more psychological problems. Assumption which is based On is That Difficulties Related To Care From Son problematic, Parents and Specially leaves Mothers Exposed to the dangers Related To Mental Health which affect children and his performance (Olson and Huang, 2001; McConkey et al, 2007). Mother is the First Person That Establishes Straight Relationship with the Children. Problems that Mothers face With Children , the Children need for Ongoing care, The importance of Building the Special conditions for Growth, Parents experience tension due to lack of skills, behaviors of children self-care in this group of Children, Are all the grounds to provide weakness to a normally functioned mother. Existence of such problems will have an increase in average non marital satisfaction of the mothers of disabled children compared with mothers of normal children. Also, the expectations away from the ability of children and in its wake not meeting the expectations cause the failure of parents (Hind, 2004; quoted mehrabi, 1383). In total, these conditions can cause stress in the field of child development, lack of interest in relation to the environment, a sense of low self-esteem and mother's worthlessness and negative consequences such as low self-efficacy, anxiety, aggression (Narimani et al, 2007), low self-esteem and severe depression (lajevardi, 1371) to be followed in children's and their health risks (Mohammadi, Dadkhah, 1381). Efficacy of social cognitive theory, Albert Bandura (1997) is derived that beliefs or judgments of a person refers to his or her abilities to perform the duties and responsibilities (Karadenas, 2007; quoted Maher, 1386). Knowledge and understanding of their individual capabilities is known as efficacy. This concept have been studied for nearly three decades by psychologists and theorists (Harington and Olson, 2005; quoted Saif al, 1385).refers To feel self-esteem, self worth, a sense of efficacy in dealing with life (Bandura, 1997; quoted Seif et al, 1380). , At the age of eight children in his own descriptions is less objective and is more focused on psychological aspects. ) and often compare themselves to others and thus lay the foundations of self-efficacy in children (Harington, 2000; Toozandehjani and Kamalipour translation, 1380) Self-efficacy is the result of the interaction of organism and environment. It can be said simply believing one's self features include: needs, motivations, attitudes, abilities, knowledge and understanding that forms behavior patterns (Amini, 1375). Most sociologists and psychologists have mentioned that some positive self-concept to be synonymous with high self- 


\section{The Relation between Parenting Stress and Marital Satisfaction of Mother with Efficacy Students with Visual Impairment, a Relation Design}

efficacy and some self-esteem to be synonymous with efficacy (Marchty, 2002, quoted by gohari, 1377). Research has shown that , there is a relation between parents, parenting styles and self-efficacy (crown , 1996; Moore, 1998; quoted by Fathi ashtiani, 1378). National self efficacy, is now one of the distinguishing factors of advanced and backward nations. Studies have shown that human resource of advanced countries have high efficacy and hence trying to increase the features of long-term plans countries around the world And high-efficacy is directly related to marital satisfaction and parenting styles (Ross, 2002; quoted by Karim Zadeh,1380).

On the other hand parenting process refers with knowledge in every aspect of health, physical development, personality, mental, emotional, emotional, social, from infancy to adulthood (Isaacs, 1995; quoted by Rajayi, 1387). Parents who waver in their communication, lack of confidence and disagree with stability in the upbringing of their children, the parenting based on pattern of exclusion, extreme protection with negligible or control, dual discipline, moral standards emotional frailty using bulk their behavior in children neurotic the consolidation and dumped into the emotional and affective children in dire need and in such circumstances the sense of trust and security that the healthy emotional development of numerous fails (yrehcireB, 1998, quoted by Dehghanpoor and Khrazchi, 1377). On the other hand, Marriage satisfaction refers To feel Happiness, Satisfaction And Pleasure By Female Or Husband when they consider All Aspects Of Marriage, (Hawkins, 2003; quoted by Sana'i, 1378). By definition, a couple's marital satisfaction is defined in the dictionary as a performance and appropriate behavior based on traditional tasks, customary law for each of them in family (danaee, 1391). Also, Ellis (1989) States that marital satisfaction and feeling of happiness, satisfaction, and joy experienced by the husband or wife when they consider all aspects of their marriage (Soleimanian, 1373). As mentioned, each Family has a Special Style in their children's Upbringing Under the Title of Parenting which is affected From different Factors like Cultural factors. most of the disorders and incompatibility of Children caused by attention deficit often is in this sensitive period (Hall, 2000; quoted by nejati 1379). Given the importance of these issues and concerns in regard to the application of prevention and treatment, aimed to study the relationship between mother's parenting stress and marital satisfaction, self-efficacy (related to parenting stress with the efficacy of students) and students with visual impairment and blindness.

\section{ETHICAL PRINCIPLES}

In this study, the informed consent was obtained without coercion, threat, enticement and seduction and their decision to refuse or accept to participate in the study were respected. It was also tried that the research methods do not contradict with the religious and cultural principles of the participants and the participants were respected in all stages of design, implementation and reporting in terms of human dignity, respect and protection of their physical and mental integrity so that conducting the research would not delay in the process of medical care for the participants. 


\section{Size of Sample}

Given that the statistical method in this research is correlation and regression analysis and in regression analysis, sample size must be between 20 to 25 times of predictor variables (Homan, 1381) Thus, with regard to twenty participants for each of the three ranging study of 60 subjects were used in this study.

$$
N=3 \mathrm{q}=3 \times 20=60
$$

\section{Statistical Analysis}

In the present study due to the nature of the study and previous research to examine the relation between three variables of parenting stress, marital satisfaction and self-efficacy and according to the distance of the scale of all three parametric test, regression analysis and Pearson test the significant relation were analyzed by t-test.

\section{METHOD}

This study is a causal-comparative plan and solidarity in the field of descriptive design. The target formed a population included all 12-22 year-old male students with visual impairment living in Tehran and Karaj. The presented study data were collected in a survey in 1393 during 1 June until 1 March, using questionnaires and clinical interviews. For this purpose sixty $(\mathrm{N}=60)$ students were selected through convenience sampling. The method of collecting data was survey and indicators to measure parenting stress, job satisfaction and self-efficacy questionnaire by Schiffer, Enrich and general self-efficacy were used. Data collected were used with Pearson correlation test, F-test and regression analysis. As well as qualitative data were analyzed obtained from the assessment coding demographic and qualitative data analysis tool ATLAS.ti 5.2. In the first stage with the kind permission of the Department of Education and in coordination with the school administrators to inform parents and students of the overall objectives of the research, the questionnaire was available to parents and students. Then the parents and students were asked to carefully and fully complete the questionnaire. After completing questionnaires from parents and students in this study were appreciated.

\section{Instruments}

- Enrich paired Scale: This Likert questionnaire consists of 35 items that evaluate potential problematic areas and identify areas of strength used in the marital relationship. By David Olson and Amy Olson couple Enrich Inventory questionnaire in 2000 was conducted on 25,501 married couples. Alpha coefficients for subscales of marital satisfaction questionnaire, communication, conflict resolution, and idealistic distortion, respectively, 0.86, 0.80, 0.84, 0.83 and test-retest reliability for each subscale questionnaire in order $86 / 0,81 / 0,90 / 0,92 / 0$ reported. In this comfortable research comfortable alpha coefficient of the questionnaire (1389) with 365 couples, respectively 0.68 (with the removal of question 24 is an alpha 0.78), 0.78, 0.62 and 0.77 on the Came. Mirkheshti research in Iran (1375), Mahdavian (1376), Moradi (1380), Sanaee (1381), 


\section{The Relation between Parenting Stress and Marital Satisfaction of Mother with Efficacy Students with Visual Impairment, a Relation Design}

haghshenas (1383) have shown that the scale of Utrecht and Persian translations of validity and reliability is required.

- Parenting stress Inventory (PSI): questionnaire with Items 101 of by Abdin 1967 is designed and based on the level of stress in the evaluation of the child's parents. The questionnaire is based on the principle that stress (stress) of some of the features of parenting children and some directly related to the characteristics of parents who are affected by it (Abdin, 1995, translated by Alizadeh, 1388). Short form of parenting stress test with 36 questions to evaluate three subscales Discomfort of parents, the child and the child dysfunctional interaction designed is difficult. Short form of Parenting stress test is involved in the credit of long form, (Abdin, 1995). Because it was adapted directly. At the same time validity combined score of 101 longform question, parenting stress, 95\% have been reported (Abdin, 1995; quoted by K., 1388). Estimate the reliability of the test - retest and internal consistency of the scale composite (combined), 91\%have been reported (Abdin, 1995; quoted from K., 1388). Test-retest reliability by 53 women with an interval of 6 months and reliability of the overall stress of 84\% was achieved, as well as reliability of the questionnaire in the study Abdin. (1388) using Cronbach's alpha equal to $92 \%$ have been reported.

- Adolescent social self-efficacy scale: Adolescent social self-efficacy scale in 1989 by Kennelly was made in order to measure efficacy in adolescents. This is a self-report tool, which has 25 items. Adolescent social self-efficacy scale has five subscales: social decisiveness, performance in social situations, participate in social groups, aspects of friendship and intimacy, help or assistance, total scores between 25-175, and higher scores indicate participants are high levels of social self-efficacy. Cronbach's alpha coefficient of the test in the first group 0.90, 0.92 in the second group and the third group was 0.95 . Retest reliability of the method in the first two weeks of 0.94 is at a distance of retest reliability coefficient for men as well as women's 0.81 and 0.86 have been reported. A significant positive correlation between self-efficacy scale scores adolescents and their perception scale silhouette was seen in the first and second groups (Harter, 1982). It also scores of this scale and scale compatibility between high school student surveys to evaluate the Group has significant correlation (Printz et al, 1978). 


\section{RESULTS}

\section{Demographic features of the participants}

Table1: Demographic status of the participants of the study

\begin{tabular}{|c|c|c|c|c|c|c|c|c|c|}
\hline 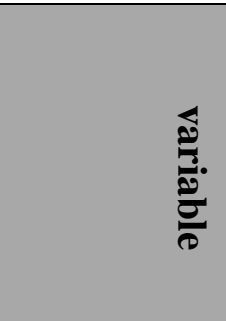 & & 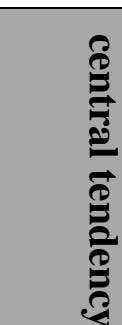 & & & 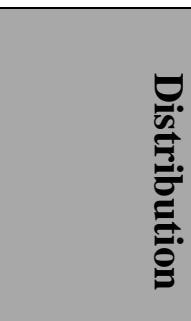 & & & 昜 & \\
\hline & $\begin{array}{l}\bar{\partial} \\
\text { ลे }\end{array}$ & 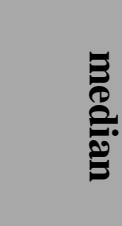 & $\begin{array}{l}3 \\
3 \\
\stackrel{3}{0}\end{array}$ & & . & $g$ & 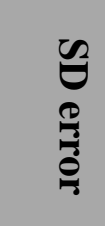 & 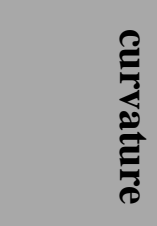 & 䍖 \\
\hline $\begin{array}{l}\text { Parenting } \\
\text { stress }\end{array}$ & 84 & 102 & 107 & 97 & 727.4 & 26.97 & 3.93 & 0.43 & -.88 \\
\hline $\begin{array}{l}\text { Efficacy } \\
\text { students }\end{array}$ & 120 & 116 & 109.6 & 131 & 900 & 30 & 4.16 & -0.79 & -0.003 \\
\hline $\begin{array}{l}\text { Academic } \\
\text { efficacy }\end{array}$ & 33 & 35 & 34.07 & 44 & 100.90 & 10.04 & 1.36 & $\begin{array}{l}-0.63 \\
\end{array}$ & -0.37 \\
\hline $\begin{array}{l}\text { Social } \\
\text { efficacy }\end{array}$ & 37 & 33 & 33.05 & 40 & 84.74 & 90.20 & 1.26 & -0.50 & -0.15 \\
\hline $\begin{array}{l}\text { Emotional } \\
\text { efficacy }\end{array}$ & 105 & 37 & 36.54 & 44 & 119.59 & 10.93 & 1.50 & -0.61 & -0.37 \\
\hline $\begin{array}{l}\text { marital } \\
\text { satisfaction }\end{array}$ & 105 & 107 & 108 & 46 & 62.10 & 7.88 & 1.12 & 0.4 & 2.02 \\
\hline
\end{tabular}

As seen in Table 1, statistical indicators are proposed, such as mean, median, standard deviation and the Elongation.

\section{Kolmogorov-Smirnov test}

As you are aware, one of the preconditions for the use of parametric tests, is normality of distribution in research variables, the Kolmogorov-Smirnov test was used to investigate the above preconditions that results is provided in Table 2 .

Table 2: results of Kolmogorov-Smirnov test

\begin{tabular}{|l|l|l|}
\hline Variable & $\mathbf{Z}$ & Sig. \\
\hline Parenting stress & 0.83 & 0.49 \\
\hline Academic efficacy & 0.98 & 0.29 \\
\hline Social efficacy & 0.83 & 0.48 \\
\hline Emotional efficacy & 0.88 & 0.41 \\
\hline
\end{tabular}


According to the results in Table 2, it can be concluded that all variables studied were normal, as a result to evaluate the assumptions of the study parametric tests can be used.

\section{Regression analysis}

In order to investigate the contribution of predictive variables in explaining the dependent variable regression analysis, the results are presented in Table 3.

Table 3: result the Regression analysis

\begin{tabular}{|l|l|l|l|l|l|}
\hline $\begin{array}{l}\text { Resource } \\
\text { changes }\end{array}$ & SS & df & Mean & df & Sig. \\
\hline Regression & 6967.13 & 2 & 3483.5 & & \\
\hline residual & 30319.8 & 38 & 797.8 & 4.36 & 0.02 \\
\hline Total & 37286.9 & 40 & - & & \\
\hline
\end{tabular}

According to the table above and the significant level calculated to be acknowledged that the explanatory power of self-efficacy students through the variable mother's parenting stress and marital satisfaction is significant, between self-efficacy variable mothers' parenting stress and marital satisfaction there is a significant relationship between students. For a more detailed the regression coefficients explanations are presented in Table 4.

Table 4: Regression coefficients of the variables parenting stress and marital satisfaction

\begin{tabular}{|l|l|l|l|l|l|}
\hline Factors & B & SD & Beta & T & Sig. \\
\hline Constant & 100.91 & 79.08 & - & 1.27 & 0.21 \\
\hline $\begin{array}{l}\text { Parenting } \\
\text { stress }\end{array}$ & 0.42 & 0.17 & -0.37 & -2.37 & 0.02 \\
\hline $\begin{array}{l}\text { marital } \\
\text { satisfaction }\end{array}$ & 0.48 & 0.64 & 0.11 & 0.75 & 0.45 \\
\hline
\end{tabular}

Through the table above and reference to the amount of the calculated beta -0.37 And 0.11 it can be acknowledged that parenting stress has more ability to explain and predict the efficacy of the students.

Table 5: The correlation coefficient between mothers' parenting stress and self-efficacy

\begin{tabular}{|l|l|l|l|l|l|}
\hline Variable & Correlation & Coefficient & Direction & $\mathbf{R}^{2}$ & Sig. \\
\hline $\begin{array}{l}\text { Parenting } \\
\begin{array}{l}\text { stress and } \\
\text { efficacy }\end{array}\end{array}$ & Pierson & -0.31 & Negative & 0.10 & 0.05 \\
\hline
\end{tabular}

According to the table above and the obtained correlation (-0.31) can be concluded that between stress and parenting efficacy in students. Also, due to the negative correlation can be concluded that the higher the mother's parenting stress, lower self-efficacy of the students coefficient 
amount of determination $10 \%$ shows that 10 percent of self-efficacy of the students with their stress levels is predictable.

The correlation scatter plot

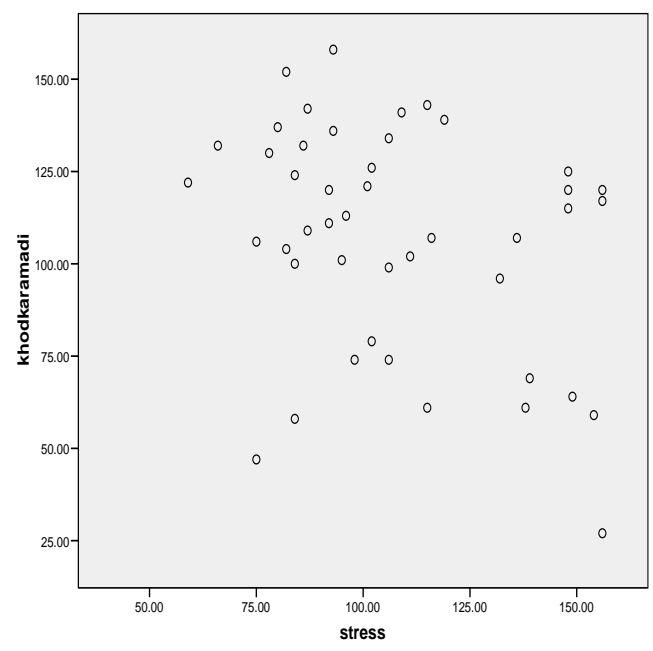

Figure 1: Distribution correlation between mothers' parenting stress and self-efficacy

Table 6: The correlation coefficient between mothers' parenting stress and self efficacy

\begin{tabular}{|l|l|l|l|l|l|}
\hline Variable & Correlational & Coefficient & Direction & $\mathbf{R}^{2}$ & Sig. \\
\hline $\begin{array}{l}\text { Maternal } \\
\text { marital } \\
\text { satisfaction } \\
\text { and self } \\
\text { efficacy }\end{array}$ & Pierson & 0.23 & positive & 0.5 & - \\
\hline
\end{tabular}

According to the results presented in Table 6, the observed correlation coefficient is not significant.

Table 7: The correlation coefficient between mothers' parenting stress and self efficacy

\begin{tabular}{|l|l|l|l|l|l|}
\hline Variable & Correlational & Coefficient & Direction & $\mathbf{R}^{2}$ & Sig. \\
\hline $\begin{array}{l}\text { Marital } \\
\text { satisfaction } \\
\text { and parenting } \\
\text { stress of } \\
\text { mothers }\end{array}$ & Pierson & -0.38 & Negative & 0.14 & 0.05 \\
\hline
\end{tabular}

According to the table above and the amount of calculated correlation (-0.38) that are meaningful in 0.5 , it can be said that there is significant relation between parenting stress and marital satisfaction. Also, due to the negative correlation can be concluded that the higher the mother's 
marital satisfaction, it reduces the parenting stress. Coefficient of determination shows that 14 percent of marital satisfaction with maternal stress is predictable.

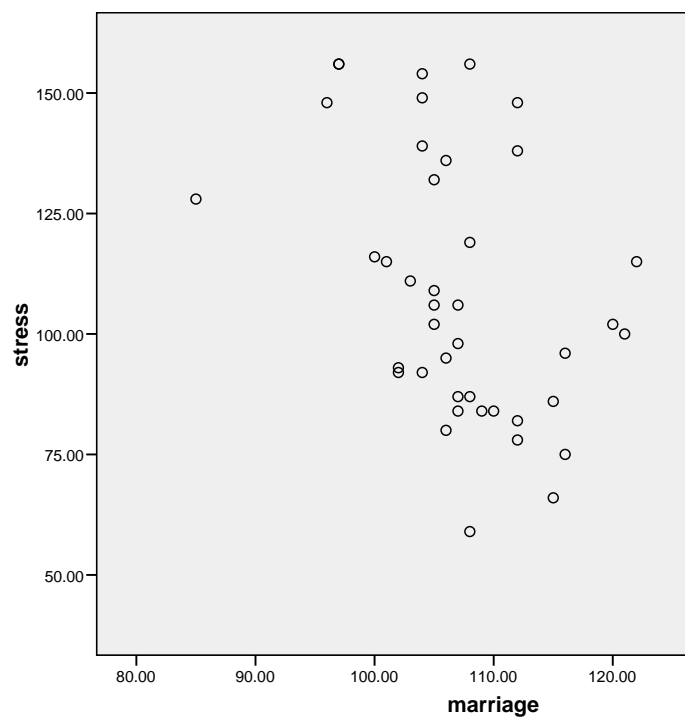

Figure 2: Distribution correlation between marital satisfaction and parenting stress of mothers

Table 8: Correlation coefficient between parenting stress and academic self-efficacy

\begin{tabular}{|l|l|l|l|l|l|}
\hline Variable & Correlational & Coefficient & Direction & $\mathbf{R}^{2}$ & Sig. \\
\hline $\begin{array}{l}\text { parenting } \\
\text { stress and } \\
\text { academic } \\
\text { self-efficacy }\end{array}$ & Pierson & -0.35 & Negative & 0.12 & 0.05 \\
\hline
\end{tabular}

According to the table above and the amount calculated correlation (-0.35) In 0.05 level is significant that one can believe that there is a significant relationship between parenting stress and self-efficacy in education of children,. Also, due to the negative correlation can be concluded that the higher the mother's parenting stress, academic self-efficacy is reduced. Coefficient of determination shows that 12 percent of their students' academic performance is predictable with their stress. 
The Relation between Parenting Stress and Marital Satisfaction of Mother with Efficacy Students with Visual Impairment, a Relation Design

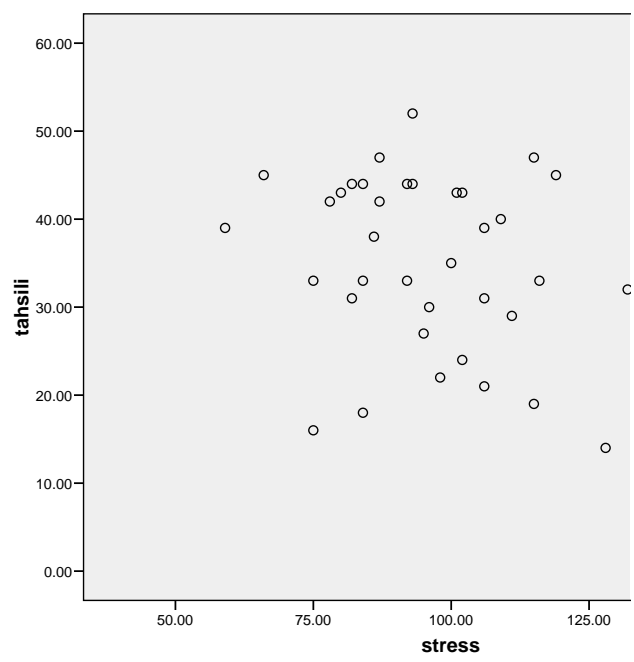

Figure 3: Distribution correlation between mothers' parenting stress and academic selfefficacy

Table 9: Correlation coefficient between Mothers' parenting stress and social self-efficacy

\begin{tabular}{|l|l|l|l|l|l|}
\hline Variable & Correlational & Coefficient & Direction & \multicolumn{1}{|c|}{$\mathbf{R}^{2}$} & Sig. \\
\hline $\begin{array}{l}\text { parenting } \\
\text { stress and } \\
\text { social self- } \\
\text { efficacy }\end{array}$ & Pierson & 0.27 & Negative & 0.07 & - \\
\hline
\end{tabular}

The calculated amount is significant And it can be concluded that there is a strong correlation between the two variables.

Table 10: Correlation coefficient between Mothers' parenting stress and emotional selfefficacy

\begin{tabular}{|l|l|l|l|l|l|}
\hline Variable & Correlational & Coefficient & Direction & $\mathbf{R}^{2}$ & Sig. \\
\hline $\begin{array}{l}\text { Mothers' } \\
\text { parenting } \\
\text { stress and } \\
\text { emotional } \\
\text { self-efficacy }\end{array}$ & Pierson & -0.28 & Negative & 0.08 & - \\
\hline
\end{tabular}

The calculated amount is significant and it can be concluded that there is a strong correlation between the two variables. 
The Relation between Parenting Stress and Marital Satisfaction of Mother with Efficacy Students with Visual Impairment, a Relation Design

Table 11: Correlation coefficient between Maternal marital satisfaction and academic selfefficacy

\begin{tabular}{|l|l|l|l|l|l|}
\hline Variable & Correlational & Coefficient & Direction & $\mathbf{R}^{2}$ & Sig. \\
\hline $\begin{array}{l}\text { Mothers' } \\
\text { parenting } \\
\text { stress and } \\
\text { emotional } \\
\text { self-efficacy }\end{array}$ & Pierson & 0.29 & Positive & 0.08 & 0.05 \\
\hline
\end{tabular}

According to the results table above and the amount calculated correlation (0.29) at the significant level of $05 / 0$, it can be said that there is a significant relationship between marital satisfaction and self-efficacy among the blind school children. Also, due to the positive correlation can be concluded that the higher the mother's marital satisfaction, the higher the selfefficacy of high school students 0.80 amount of coefficient of determination shows that 8 Percent of their students' academic performance is predictable with their marital satisfaction.

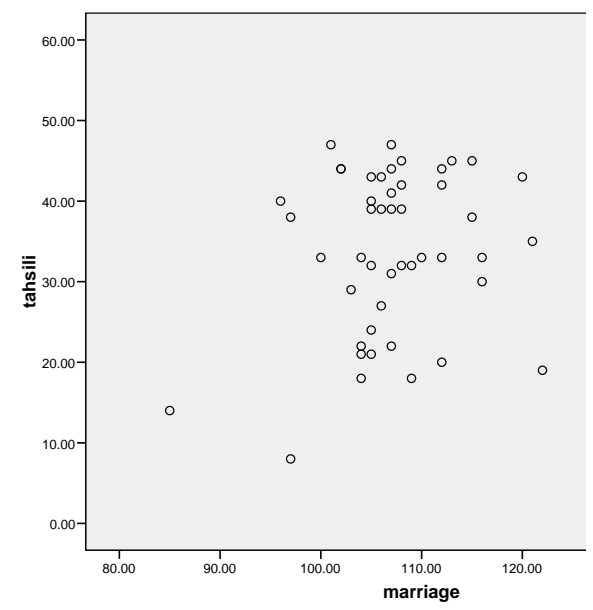

Figure 4: Distribution correlation between marital satisfaction and academic self-efficacy

Table 12: Correlation coefficient between maternal marital satisfaction and social self-efficacy

\begin{tabular}{|l|l|l|l|l|l|}
\hline Variable & Correlational & Coefficient & Direction & $\mathbf{R}^{2}$ & Sig. \\
\hline $\begin{array}{l}\text { Mothers' } \\
\text { parenting } \\
\text { stress and } \\
\text { emotional } \\
\text { self-efficacy }\end{array}$ & Pierson & 0.32 & Positive & 0.10 & 0.05 \\
\hline
\end{tabular}

According to the table above and the amount calculated correlation (0.32) at the significant level of 0.05 , it can be said that there is a significant relationship between marital satisfaction and social self-efficacy among children. Also, due to the positive correlation can be concluded that the higher the mother's marital satisfaction, the higher is the self-efficacy of students. Amount of 
coefficient of determination $10 \%$ shows that $10 \%$ of social self-efficacy students with marital satisfaction of their mother is predictable.

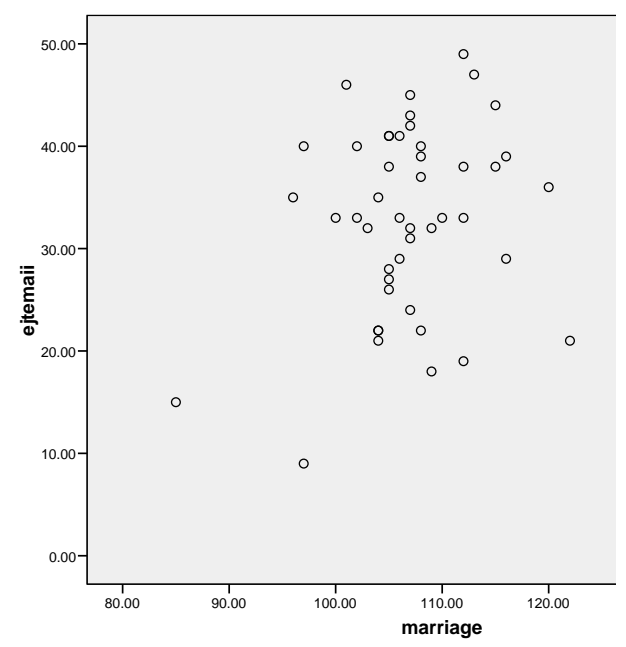

Figure 5: Distribution correlation between marital satisfaction and social efficacy

Table 11: Correlation coefficient between Maternal marital satisfaction and emotional selfefficacy

\begin{tabular}{|l|l|l|l|l|l|}
\hline Variable & Correlational & Coefficient & Direction & $\mathbf{R}^{2}$ & Sig. \\
\hline $\begin{array}{l}\text { Mothers' } \\
\text { parenting } \\
\text { stress and } \\
\text { emotional } \\
\text { self-efficacy }\end{array}$ & Pierson & 0.22 & Positive & 0.05 & - \\
\hline
\end{tabular}

The calculated amount is not significant And it can be concluded that there is a connection between the two variables.

\section{DISCUSSION}

After a study of the relationship between parenting stress and marital satisfaction of efficacy students with visual impairment and blindness was performed. The results showed that there is significant relation between parenting stress and marital satisfaction with self-efficacy of children. Between parenting stress of mothers with three levels of academic self-efficacy ( $\mathrm{r}=-$ $0.35)$, Social $(r=-0.27)$ And emotional $(r=-0.28)$ A significant relationship exists. The results showed that the share of parenting stress in mothers define self-efficacy students more than the share of mother of marital satisfaction. There is also a significant inverse correlation observed between the two components of marital satisfaction and parenting stress.

Yaghob Khani (1372), mehrafroz (1381), Hosseini nesbat (1387), Kimberley (1386), Kimberley et al (2010) in their study concluded that there is significant relation and negative correlation in 
parenting stress with efficacy .In this regard valizadeh (1390) in his study je carried samples consisted of 304 students that aims to determine the role of self-esteem and self-concept of intermediary in the relationship between parenting styles and academic achievement that the direct effects of three permissive parenting styles, authoritarian and authoritative are significant academic achievement requirements. Yousefi (1386) in his study With the Title Relationship Style of parenting by parents With social Skills And Aspects From Self-concept Knowledge of High school Students, the results of his study suggests That Iranian Children that Belong To decisive Families completely lack less social skills. In another study yaghobkhani (1372) on the effects of family environment on children's achievement showed the warmth of family is positively correlated with academic achievement. Warm and more controlled Families showed more success. Johnston and Chen (2010) showed in their studies that the overall academic achievement of students with authoritarian parenting style have no negative relationship with the authoritarian style of communication (bitaraf, 1389). On the other hand Henriksen and Rocker (2000) have been shown in their research that styles of parenting, especially supportive parenting styles, led to the formation of children and adolescents, while the lack of support and the use of authoritarian methods leads to various problems such as substance abuse and dropout. Schunk (1996) in his study showed, positive academic motivation and academic achievement are linked with authoritative style. This style provides background which through it parents reinforce children's independence and individuality; they create opportunities for the family to decide on their participation. In several studies (Dornbusch et al, 1987; Lamborn et al, 1991; Steinberg et al, 1994) shows that authoritarian, permissive, and neglectful stringent fee has a negative correlation with academic achievement.

\section{STUDY LIMITATIONS}

This study is similar to other studies of people with limitations such that it can be used as follows: 1) the presented study only been used within the students with impaired vision com and

2) lack of control in other factors affecting the efficacy of the limitations of the present study can be outlined.

\section{RESEARCH IMPLICATIONS}

Going on to mention several proposals in order to apply in future studies: 1) It is recommended that efficacy be reviewed in other exceptional groups as well as others , 2) it suggests that selfefficacy be reviewed in college students and other ages 3) is recommended in order to assess the efficacy female sample be used.

\section{Acknowledgments}

The author appreciates all those who participated in the study and helped to facilitate the research process.

\section{Conflict Of Interests}

The author declared no conflict of interests. 


\section{REFERENCES}

Bandura, A. (1997). Social cognitive theory of self-regulation. Organizational Behavior and Human Decision Processes, 50, 248-287.

Dornbusch, S.M., Ritter, P. L., Leiderman, R. H., Roberts, D. F., \& fraleigh, M. Y. (1987). The relation of parenting style to adolescent school performance. Child development,58, 1294-1254.

Hind, A.M. Hammouri .(2004). Attitudinal and motivational Variables related to mathematics achievements in Jordan. Educational Research, 46, 3

Karademas, E.(2007). "Positive and negative aspects of well-being: Common and specific predictors”. Personality and Individual Differences , 43, 277- 287.

Lajevardi Z.(1992). [Comparison of depressed mothers can teach mentally retarded children and normal children]. M.Sc. Dissertation. Tehran: Tehran University. 11-26. (Persian)

Lamborn, S. D., Mants, N. S., Steinberg, L., \& Dornbusch, S. M. (1991). Patterns of competence and adjustment among adolescents form authoritative, authoritarian, indulgent, and neglectful families. Child Development, 62, 1049-1056.

McConkey, Rxz., Truesdale-Kennedy, M., Chang, M., Jarrah, S., and Shukri, R. (2007). “The impact on mothers of bringing up a child with intellectual disabilities: A cross-cultural study”. International Journal of Nursing Studies (in press) Published Online October 2006

Michaeli, F. Structural relationships between psychological well-being and emotional intelligence perceived ability to control depression in mothers of children with disabilities and comparing them negatively with the normal Madera Research on Exceptional Children, 2009, Vol.9, No. 2, 103-120

Mohammadi M, Dadkhah B.( 2001). [Psychological and social problems compared to parents of mentally retarded children under the Welfare of Ardebil]. Journal of Rafsanjan University of Medical Sciences; 1(3): 206-20. (Persian)

Narimani M, Aqamohammadian H, Rajabi S.(2007). [Mental health compared to children with exceptional mental health of mothers of normal children]. Journal of fundamentals of mental health; 9(1-2):15-24. (Persian)

Olsson, M. B., \& Hwang, C. P. (2001). "Depression in mothers and fathers of children with intellectual disability”, Journal of Intellectual Disability Research, 45, 535-545.

How to cite this article: N Asadi (2016) The Relation between Parenting Stress and Marital Satisfaction of Mother with Efficacy Students with Visual Impairment, a Relation Design, International Journal of Indian Psychology, Volume 3, Issue 3, No. 5, DIP: 18.01.088/20160303 